Nigerian Journal of Physiological Sciences 23 (1-2): 67 - 70 @Physiological Society of Nigeria 2008 Available online/abstracted at http://www.bioline.org.br/np; www.ajol.info/journals.njps; www.cas.org

\title{
THE INFLUENCE OF PARITY ON THE GESTATIONAL AGE AT BOOKING AMONG PREGNANT WOMEN IN ENUGU, SOUTH EAST NIGERIA
}

\section{U. I. NWAGHA. O. V. UGWU ${ }^{1}$, T. U NWAGHA ${ }^{2}$ and U. S. B. Anyaehie ${ }^{3}$}

Department of Physiology/Obstetrics and Gynaecology, College of Medicine, University of Nigeria, Enugu campus Nigeria. ${ }^{1}$ Department of Obstetrics and Gynaecology, University of Nigeria Teaching Hospital, Enugu. ${ }^{2}$ Department of Haematology/Community Medicine, University of Nigeria Teaching Hospital Enugu. ${ }^{3}$ Department of Physiology, College of Medicine, University of Nigeria, Enugu campus. Tel: +234 $0803 \quad 3128$ 233, E-mail: uchenwagha@yahoo.com.

Summary: Antenatal care utilization is influenced by several factors. Due to our peculiar socioeconomic and cultural circumstances, gestational age at booking may be affected by certain variables. The aim of this study was to determine the influence of parity and other socio demographic factors on gestational age at booking amongst pregnant women in Enugu, South Eastern Nigeria. This is a prospective multicenter survey of randomly selected 928 pregnant women attending antenatal care for the first time in three hospitals in Enugu between January1 2006 to December 31,2007 . The average age was $30.22 \pm 5.2$ yrs. The average age of the primigravidae at booking was $29.16 \pm 5$.6yrs. The average gestational age at booking for all the pregnant women studied was $26.12 \pm 7.6$ weeks Parity significantly $(\mathrm{P}<0.05)$ influenced the gestational age at booking $(24.00 \pm 7.9$ weeks versus $27.16 \pm 7.5$ weeks versus $26.12 \pm 7$.6weeks for the primigravidae, multigravidae and grandmultiparous women respectively. 856 (92.24\%) booked late for antenatal care after the first trimester. Occupation did not have significant influence on gestational age at booking. It is concluded that parity significantly influenced the gestational age at booking in Enugu.

Key words: Antenatal care, Parity, Socio-dermographic characteristics

\section{Introduction}

The first antenatal visit otherwise known as the booking visit should ideally be at the first trimester, between 8-14 weeks (WHO 2001, Campell and Lees 2000) The main purpose of this visit is to obtain a comprehensive history, establish gestational age and identify any maternal or fetal risk factors (WHO 2001). Thus, booking at this appropriate period has been associated with significant reduction in maternal and perinatal morbidity and mortality (Carroli et al 2001). In view of this objective, the gestational age at booking should ideally not be influenced by parity, occupation or indeed other socio-demographic factors. The main focus should be the reduction of adverse pregnancy outcomes. Poverty, ignorance unstable political and economic environments and socio-cultural beliefs may influence the woman's attitude towards early booking for antenatal care.

In Nigeria, especially at the South Eastern region, there is little information on influence of parity on the gestational age at booking. This study therefore assessed the influence of parity and other socio-demographic factors on the gestational age at booking.

\section{Subjects and Method}

After an informed oral consent and ethical clearance from the relevant authority, pregnant women attending antenatal care for the first time at University of Nigeria Teaching Hospital, Kenechukwu Specialist hospital and Chukwuasokam maternity hospital all in Enugu between $1^{\text {st }}$ January 2006 and $31^{\text {st }}$ December 2007 were randomly selected by a lucky dip of yes or no. The inclusion criteria included all those who at booking were sure of the date of their last menstrual period with compatible uterine size. It also included those women who had first trimester pelvic ultrasound scan that corresponded with the gestational age as calculated. Those who were 'unsure of date' or those with disparity between the gestational age and ultrasound findings were excluded from the study. Also excluded were those with medical or obstetrics complication who have other indications apart from the routine antenatal booking. We obtained personal history, history of present pregnancy, past obstetric history, past medical history, family and social history and review of systems. The gestational age at booking was calculated from the last menstrual period(LMP).Trimester was defined as first trimester ( $<14$ weeks), second (14 weeks - 27 weeks) and third (>27weeks).

Complete medical and obstetrics examination was carried out. Ultrasound scan was routinely done especially those in the first trimester. 
Statistical Analysis:

Data analysis was by descriptive and inferential statistics using SPSS for windows version 11. Mean gestational age at booking and other variables were compared using Chi square . A P-value of less than 0.05 was considered statistically significant.

\section{Result}

The ages of the women studied ranged between 18-42 years, with average age of $30.22 \pm 5.1 \mathrm{yrs}$. Majority; $488(52.59 \%)$ of the women were within 20-30 years age group while $432(46.55 \%)$ were greater than 30 years. Only $8(0.86 \%)$ were teenagers. All the women $(100 \%)$ had at least primary school education and were thus literate.

The mean age of primigravidae at booking was $29.16 \pm 5$.6years. That of multigravidae and grandmultiparous women were $30.49 \pm 4$.9years and $32.61 \pm 6$ years respectively. The mean parity amongst the women studied was $1.75+0.6$. The parity ranged between 0 to 7 . Multigravidae constituted the majority and accounted for $62.07 \%$ of the women studied. The primigravidae and grandmultiparous women constituted $31.03 \%$ and $6.90 \%$ respectively. The mean gestational age at booking for all the pregnant women studied was $26.12 \pm 7$.6weeks. The gestational age ranged between 7 weeks to 40 weeks. The mean gestational age at booking for the primigravidae was $24.00 \pm 7.9$ weeks. Those of the multigravidae and grandmultiparous women were $27.16 \pm 7.5$ and $26.89 \pm 6.2$ weeks respectively. The observed differences were statistically significant $(\mathrm{X}$ $\left.{ }^{2}=425.931, \mathrm{p} \leq 0.05\right)$.

Four hundred and sixty (49.57\%) of the women booked for antenatal care in the $3^{\text {rd }}$ trimester, while $396(42.67 \%)$ booked in the $2^{\text {nd }}$ trimester. Only 72 $(7.76 \%)$ of the women studied booked in the $1^{\text {st }}$ trimester. The mean gestational age at booking for the housewives, students, traders and civil servants were $25.95 \pm 6.5$ weeks, $25.78 \pm 8$.3 weeks, $25.89 \pm 7.9$ weeks and $26.42 \pm 7.9$ weeks respectively. The observed differences were not statistically significant $(\mathrm{P} \geq 0.05)$. These findings are presented in Tables 1 and 2 and Figures 1 and 2.
Table I: Age and trimester distribution at booking.

\begin{tabular}{llc}
\hline Variables & Number & $\begin{array}{l}\text { Percentage } \\
(\%)\end{array}$ \\
Age(yrs) & & \\
$<19$ & 8 & 0.86 \\
$20-30$ & 488 & 52.59 \\
$>30$ & 432 & 46.55 \\
Trimester & & \\
First & 72 & 7.76 \\
Second & 396 & 42.67 \\
Third & 460 & 49.57 \\
\hline
\end{tabular}

Table 2: The influence of parity on the gestational age at booking

\begin{tabular}{|c|c|c|c|}
\hline Variable & Number & $\%$ & $\begin{array}{c}\text { Gestational } \\
\text { age at } \\
\text { booking }\end{array}$ \\
\hline \multicolumn{4}{|l|}{ Parity } \\
\hline *Primigravidae & 288 & (31.03) & $24 \pm 7.9$ \\
\hline Multigravidae & 576 & $(62.07)$ & $27.16 \pm 7.5$ \\
\hline Grandmultipara & 64 & $(6.90)$ & $26.89 \pm 6.2$ \\
\hline
\end{tabular}

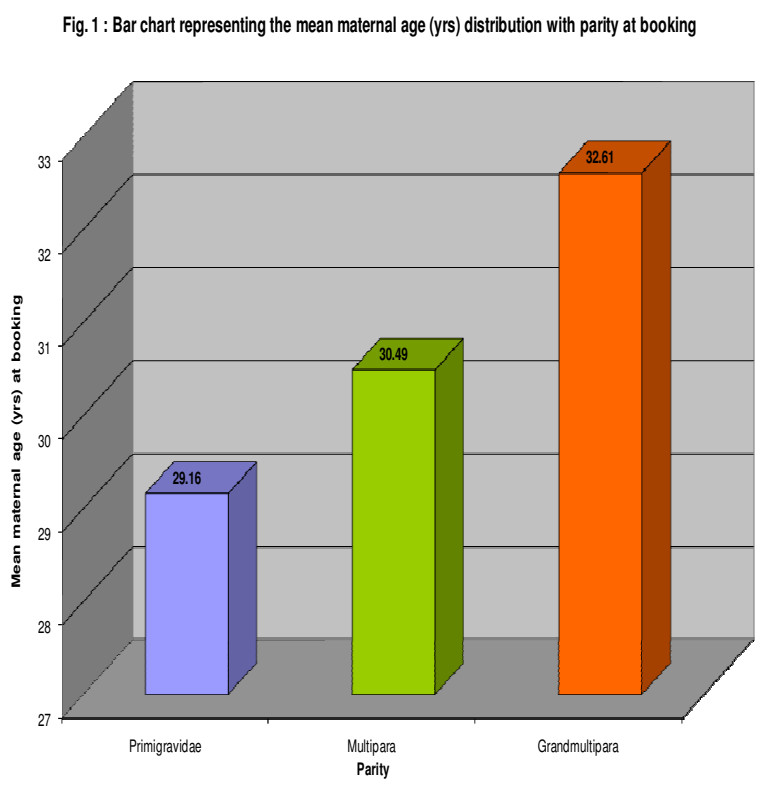


Fig. 2 : Line graph representing the influence of occupation on gestational age (weeks) at booking

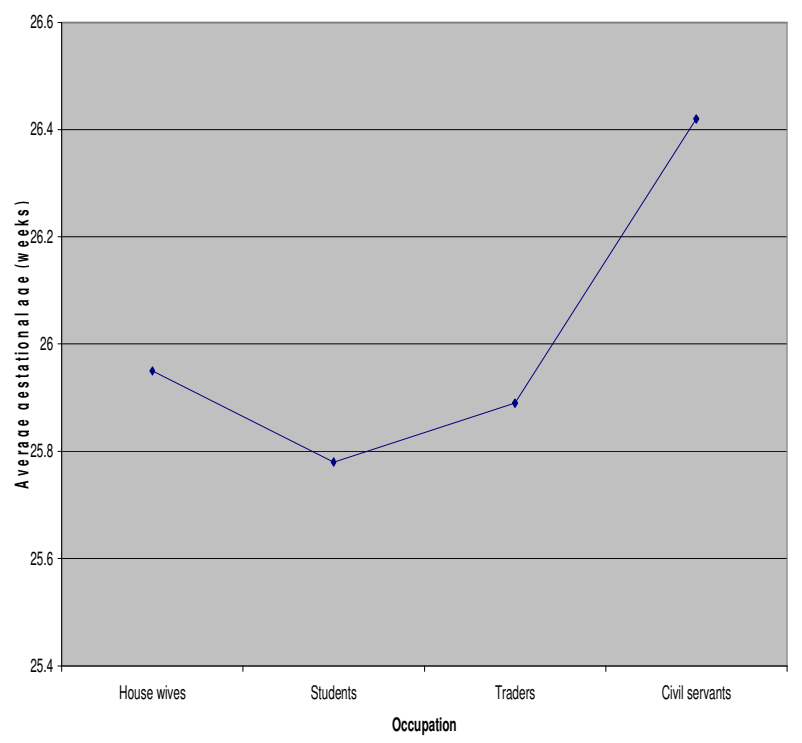

\section{Discussion}

This study revealed that parity significantly influenced the gestational age at booking. It showed that the average gestational age at booking was lowest among primigravidae, when compared with multiparous and grandmultiparous women .Similar findings were obtained among pregnant women attending antenatal care in Sokoto where the gestational age at booking amongst grandmultiparous women was significantly higher than that of the primigravidae (25.30 versus 23.08 weeks (Ekele and Audu 1998) This is also in agreement with findings from Saudi Arabia where multiparous women booked later for antenatal care because of their deceitful assurance from previous successful pregnancy outcome (Baldo et tal 1995). However, the findings are in contrast with similar study from Niger Delta, Nigeria where parity did not significantly influence the gestational age at booking (Ebeigbe and Igberase 2005).

The mean gestational age at booking for all the pregnant women was 26.12 weeks, a figure higher than 21.82 weeks at Ibadan( Okunola et al 2006), 23.68 weeks at Ilesha(Komolafe et al 2005), and 23.5 weeks reported from Sokoto (Ekele and Audu 1998). It is however lower than the 28 weeks reported amongst pregnant women in Durban, South Africa (Moodly 1993). It is therefore clear from the foregoing that pregnant women booked late for antenatal care in Nigeria and other developing countries. Hence, more health education with emphasis on benefits of early antenatal booking in the first trimester should be advocated.
The average age of primigravidae at booking in Enugu was 29.16 years. Earlier studies from Enugu has consistently showed a progressive rise in the age of primigravidae from 24.0 years in 1980 to 27.6 years in 2000 (Onah and Eze 2002, Onah 2000).

The fact that only $0.86 \%$ of the pregnant women in this study were teenagers could be explained by the current increase in female education and empowerment which discourages early marriage. Occupation did not significantly influence the gestational age at booking. This is in agreement with the study from Niger Delta which showed that social class and level of education did not influence the gestational age at booking (Ebeigbe and Igberase 2005).

We conclude that Parity has a significant influence on the gestational age at booking amongst pregnant women in Enugu, Nigeria. Early booking should be encouraged irrespective of parity. No single pregnancy is the same as the other and unexpected adverse outcome may occur despite previous uncomplicated pregnancies. This underscores the need for more health education if we must achieve the millennium developmental goals.

\section{References}

Baldo M. H. (1995). Antenatal Care, Attitudes and Practices. J. Trop. Paed. 41, Suppl, 21-29.

Campell S. and Lees, C. (eds.)(2000). Achieving the aims of Antenatal care; In: Obstetrics by Ten Teachers, $17^{\text {th }}$ edition, Arnold Publishers, Oxford .pp 87-100.

Carroli G, Rooney C, Villa J(2001). How effective is antenatal care in preventing maternal mortality and serious morbidity? An overview of evidence. Paed Perinatal Epidemiol. 15 (suppl.1): 1-42.

Ebeigbe, P. N. and Igberase, G. O. (2005). Antenatal Care;A comparison of demographic and Obstetric Characteristics of early and late attendees in the Niger delta, Nigeria. Med Sci Monit 11(11): 529-32.

Ekele, B. A. and Audu, L. R. (1998). Gestational Age at first Antenatal Attendance in Sokoto, Northern Nigeria. Trop J Obstet Gynaecol . 15(1): 39-40.

Komolafe J. O., Kuti, O., Oni, O., Egbewale, B.E. (2005) Sociodemographic characteristics of anaemic gravidae at booking: a preliminary study at Ilesha, Western Nigeria. Niger. J. Med. 14 (2): 151-154.

Moodley, J. (1993). Coping with hypertension in pregnancy. Africa Health 15 (3): 10-14.

Okunola, M. A., Avinde, O. A., Owonikoko, K. M. and Omigbodun, A. O. (2006). Factors influencing gestational age at antenatal booking 
at the University College Hospital, Ibadan Nigeria. J Obstet Gynaecol 26(3): 195-197.

Onah, H. E, and Eze, J. N. (2002). Trends in the Age of Primigravidae in Enugu, Nigeria. Trop. $J$ Obstet Gynaecol 19(2): 71-73.

Onah, H. E. (2000). Decreasing fetal growth standards in Enugu, Nigeria. Int J Gynaecol Obstet 68:219-224.
WHO Programme to Map Best Reproductive Health Practices (2001). WHO Antenatal Care Randomized Trial; Manual for the implementation of the New Model. The WHO Reproductive Health Library, No. 4, Geneva, The World Health Organization (WHO/RHR/01.30). 